\title{
Seasonal Maintenance of Influenza Vaccine-Induced Antibody Response in Kidney Transplant Recipients
}

\author{
Kelly A. Birdwell ${ }^{a}$ Mine R. Ikizler ${ }^{b}$ Li Wang $^{c}$ Daniel W. Byrne ${ }^{c}$ \\ Edith C. Sannellad Peter F. Wright ${ }^{\mathrm{e}}$ T. Alp Ikizler ${ }^{\mathrm{a}}$ \\ Divisions of a Nephrology and ${ }^{\mathrm{b}}$ Pediatric Infectious Diseases, ' Department of Biostatistics, and \\ ${ }^{\mathrm{d} V}$ Virology Laboratory, Vanderbilt University Medical Center, Nashville, Tenn., and 'Division of Infectious Disease \\ and International Health, Dartmouth Medical School, Lebanon, N.H., USA
}

\section{Key Words}

Transplant $\cdot$ Influenza $\cdot$ Vaccine $\cdot$ Immunosuppression

\begin{abstract}
Background/Aims: Although annual influenza vaccination is recommended for kidney transplant recipients, efficacy as reflected by serum antibody titers has not been well studied beyond 1 month in kidney transplant recipients. Methods: We performed a single-center prospective cohort study of 51 kidney transplant recipients and 102 healthy controls receiving the 2006-2007 influenza vaccine. Anti-hemagglutinin antibody titers to $A / H 1 N 1, A / H 3 N 2$, and $B$ were measured before and 1 month after vaccination, and again at the end of influenza season. The primary outcome was the proportion of participants maintaining seroprotection (antibody titer $\geq 1: 32$ ) for the duration of the influenza season after influenza vaccination. Results: Median follow-up time was 175 and 155 days in the transplant and control groups, respectively. For types $\mathrm{A} / \mathrm{H} 1 \mathrm{~N} 1$ and $\mathrm{B}$, a similar high proportion of the transplant and control groups ( 88.5 and $81.6 \%$ vs. 83.7 and $74.2 \%$ for $\mathrm{A} / \mathrm{H} 1 \mathrm{~N} 1$ and $\mathrm{B}$, respectively) maintained seroprotection. For type A/H3N2, significantly less of the transplant group (66.7\%) versus the control group (90\%) maintained a protective influenza vaccine response (odds ratio
\end{abstract}

$0.21,95 \%$ confidence interval $0.07-0.64)$. This difference disappeared in adjusted analyses. Actual geometric mean titers decreased significantly within both groups $(p<0.001)$ but this did not differ between groups. Conclusions: Once they have developed protective vaccine-induced antibody responses to influenza vaccine, kidney transplant recipients are able to maintain adequate protective levels of antibody compared with healthy controls.

Copyright $\odot 2012$ S. Karger AG, Basel

\section{Introduction}

Seasonal influenza is a recurrent and ongoing infectious threat to kidney and other solid organ transplant recipients. Presenting as an acute, febrile respiratory illness, influenza infection may lead to a more complicated course in these immunosuppressed individuals [1]. As a result, annual inactivated influenza vaccination is consistently recommended for kidney transplant recipients, in spite of concerns over adequate vaccine response and potential safety risks [2-4].

Changes in anti-hemagglutinin antibody titer are the best surrogate to measure influenza vaccine efficacy [5]. Several previous studies have described the initial anti-

\section{KARGER}

Fax +41613061234 E-Mail karger@karger.ch www.karger.com

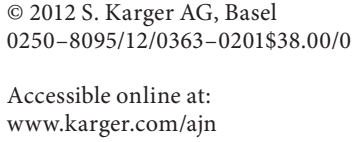


body response that occurs within the first few weeks postvaccination in kidney transplant recipients [6-14]. When comparing kidney transplant recipients with healthy controls, some of these studies have described a comparable antibody response in the two groups whereas others have described a decreased antibody response in the kidney transplant recipients. The majority of these studies have examined antibody response in the first month postvaccination. Little is known about duration of antibody response to influenza vaccine in later times in kidney transplant recipients even though the vaccine is intended to protect the recipient for the duration of the influenza season.

In a previous study, we examined the antibody response to influenza vaccination at 1 month in a prospective cohort study of kidney transplant recipients and healthy control participants [6]. In this study, we used the same cohort to compare the maintenance of a protective vaccine-induced antibody response through the end of the 2006-2007 influenza season. Based on their ongoing immunosuppression, we hypothesized that kidney transplant recipients would have a greater decrease in antibody titers compared with healthy controls at the end of the season.

\section{Methods}

\section{Study Design}

All study procedures were approved by the Institutional Review Board of Vanderbilt University Medical Center (VUMC). Informed consent was obtained from all study participants. We conducted a single-center, prospective cohort study of antibody response to the trivalent, inactivated, intramuscularly administered influenza vaccine in kidney transplant recipients on a tacrolimus-based immunosuppression regimen and healthy control participants. Kidney transplant recipients were recruited from the VUMC Renal Transplant Clinic during October and November 2006. Inclusion criteria for the transplant recipients were age 18-69 years with a functioning transplant, a tacrolimus-based immunosuppression regimen, and being more than 30 days from the transplant procedure. Healthy controls also aged $18-69$ years were recruited during the same time period. Potential participants were excluded if they had already received the 2006-2007 influenza vaccine, had known anaphylactic reactions to eggs or prior influenza vaccine, or the presence of moderate to severe acute febrile illness in the week prior to enrollment. Transplant and control participants were not matched.

The study was composed of 3 visits. At visit 1, demographic, medical, and social data was collected from each patient with confirmation of medical data via the VUMC electronic medical record. Blood was collected to measure serum creatinine and baseline influenza antibody titer. Then the 2006-2007 trivalent inactivated intramuscular influenza vaccine (Fluvirin; Chiron
Vaccines Ltd, Liverpool, UK, Lot \# 69480, expiration 6/30/2007) was administered as a single $0.5-\mathrm{ml}$ dose into the deltoid muscle. The 2006-2007 influenza vaccine contained $15 \mu \mathrm{g}$ hemagglutinin each of A/New Caledonia/20/99 (H1N1), A/Wisconsin/67/2005 (H3N2), and B/Malaysia/2506/2004 viruses. Visit 2 occurred 1 month later, with serum collected to measure post-vaccination influenza antibody titer and serum creatinine. Visit 3 (end-ofseason visit) occurred between 6 and 11 months post-vaccination, and prior to receipt of the 2007-2008 influenza vaccine. Participants were asked about adverse vaccine reactions, influenza-like illnesses or hospitalizations during follow-up visits, though no surveillance testing for infection was performed.

Anti-hemagglutinin antibody levels were measured to represent antibody response to the vaccine. Levels were obtained using serum for the hemagglutinin inhibition test and the aggregate result for a group was reported as a geometric mean titer [15]. At 1 month, a positive antibody response was defined as: (1) seroconversion, a fourfold rise in antibody titer or conversion from a negative to positive titer; (2) seroprotection, an antibody titer of 1:32 or greater, representing the $50 \%$ protective threshold [16-19]. Participants were described as having baseline seroprotection to a given influenza type $(\mathrm{A} / \mathrm{H} 1 \mathrm{~N} 1, \mathrm{~A} / \mathrm{H} 3 \mathrm{~N} 2$, or $\mathrm{B})$ if their pre-vaccination titer was already 32 or greater. We reported the results of the 1-month antibody response previously [6]. In this follow-up study, we selected those participants with seroprotection at 1 month to see if they maintained a protective level of titer throughout the season. The primary outcome was proportion of subjects that maintained a protective antibody titer of $\geq 1: 32$ (maintenance of seroprotection) at the end of influenza season. Secondary outcomes included changes in geometric mean titers. Kidney function was reported as serum creatinine in $\mathrm{mg} / \mathrm{dl}$ or as estimated glomerular filtration rate using the four-variable MDRD study equation [20].

\section{Laboratory Methods}

Three to $5 \mathrm{ml}$ of serum was aliquoted and frozen at $-80^{\circ} \mathrm{C}$ until tested for antibody response. Prior to hemagglutinin inhibition testing, serum was treated with receptor-destroying enzyme (RDE II 'Seiken'; Denka Seiken Co., Ltd, Tokyo, Japan) with 3 parts RDE to 1 part serum and incubated at $37^{\circ} \mathrm{C}$ for $18-20 \mathrm{~h}$. The samples were diluted to 1:8 with phosphate-buffered saline and then incubated at $56^{\circ} \mathrm{C}$ for $1 \mathrm{~h}$. Hemagglutinin inhibition testing was performed as previously described using the 2006-2007 WHO influenza reagent kit from CDC (Atlanta, Ga., USA) with Turkey red blood cells (CBT Farms, Chestertown, Md., USA) [21]. All samples were tested in duplicate. Serum creatinine was measured by the Vanderbilt Clinical Research Center core laboratory on the day of obtainment.

\section{Statistical Analysis}

Our initial sample size calculation was designed to test the null hypothesis that kidney transplant recipients and healthy controls would have the same antibody response to the seasonal inactivated influenza vaccine 1 month post-vaccination. Descriptive statistics were calculated as the median with interquartile range (IQR) (or mean with SD) for continuous variables. For categorical variables, frequencies and percentages were presented. Differences between control and transplant groups were assessed using Wilcoxon rank sum test or $\chi^{2}$ test. Multivariable linear regression was used to test for differences in titers between groups with ad- 


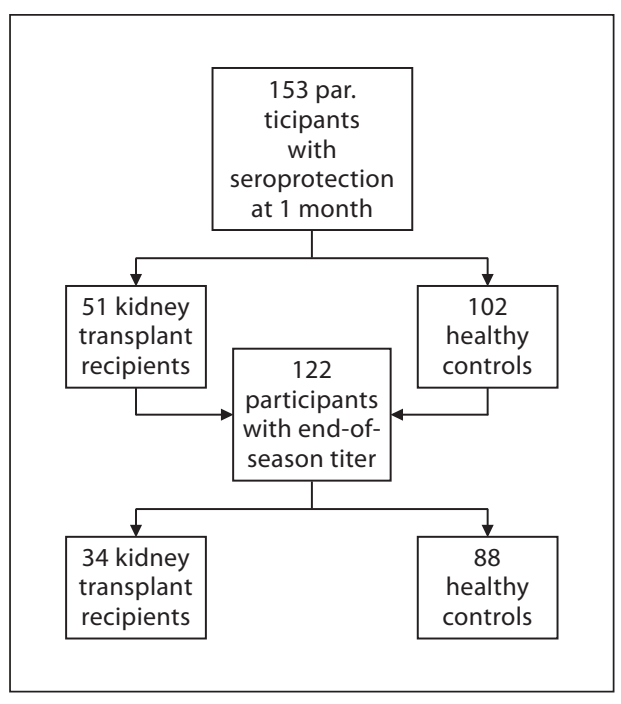

Fig. 1. Study enrollment and follow-up.

justment of other covariates. A linear mixed-effects model was used to assess the differences of titer change over time between groups. The primary endpoint was the dichotomous outcome variable of the proportion of patients maintaining seroprotection (titer $\geq 1: 32$ ) at the end of the 2006-2007 influenza season. Logistic regression was used to assess the differences between control and transplant patients with adjustment of the 1-month titer measurement, as well as age, sex, race, and baseline creatinine level via propensity score. Statistical analyses were performed with the statistical software SPSS (version 19.0; SPSS Inc., Chicago, Ill., USA) and R statistical software (version 2.13.1; R Foundation for Statistical Computing, Vienna, Austria).

\section{Results}

\section{Baseline Characteristics}

Of the 159 participants in the original cohort, 153 developed seroprotection to at least one influenza antigen type at 1 month post-vaccination and comprised the current study cohort. The baseline characteristics of the study cohort are shown in table 1 . One-third $(n=51)$ of the participants were kidney transplant recipients. Significantly more healthy control participants were women. The transplant recipients had significantly decreased kidney function compared with the healthy controls with a mean serum creatinine of $1.5 \pm 0.6$ and $0.9 \pm 0.2 \mathrm{mg} /$ $\mathrm{dl}$, respectively. Though both groups had a similar history of prior influenza vaccination, significantly less kidney transplant recipients (47\%) than controls $(69 \%)$ had baseline seroprotection to $\mathrm{A} / \mathrm{H} 3 \mathrm{~N} 2(\mathrm{p}=0.01)$ with a low-
Table 1. Characteristics of the 153 participants

\begin{tabular}{|c|c|c|c|}
\hline & $\begin{array}{l}\text { Transplant } \\
\text { recipients } \\
(\mathrm{n}=51)\end{array}$ & $\begin{array}{l}\text { Controls } \\
(\mathrm{n}=102)\end{array}$ & $\mathrm{p}$ \\
\hline Age, years & $44 \pm 10$ & $41 \pm 12$ & 0.09 \\
\hline Women & $20(39)$ & $70(69)$ & $<0.001$ \\
\hline Race $^{\mathrm{a}}$ & & & 0.003 \\
\hline White & $40(78)$ & $89(87)$ & \\
\hline Black & $10(20)$ & $4(4)$ & \\
\hline Asian & $0(0)$ & $8(8)$ & \\
\hline Other & $1(2)$ & $1(1)$ & \\
\hline Serum creatinine, mg/dl & $1.4 \pm 0.6$ & $0.9 \pm 0.2$ & $<0.001$ \\
\hline $\begin{array}{l}\text { Glomerular filtration rate, } \\
\mathrm{ml} / \mathrm{min} / 1.73 \mathrm{~m}^{2}\end{array}$ & $61 \pm 20$ & $85 \pm 18$ & $<0.001$ \\
\hline Previous influenza vaccination ${ }^{b}$ & $48(94)$ & $86(84)$ & 0.2 \\
\hline \multicolumn{4}{|l|}{ Baseline geometric mean titer } \\
\hline $\mathrm{A} / \mathrm{H} 1 \mathrm{~N} 1$ & $39.2 \pm 5.4$ & $35.8 \pm 4.5$ & 0.8 \\
\hline $\mathrm{A} / \mathrm{H} 3 \mathrm{~N} 2$ & $22 \pm 5.1$ & $41 \pm 4$ & 0.03 \\
\hline $\mathrm{B}$ & $39.2 \pm 3.9$ & $41.5 \pm 3.4$ & 0.7 \\
\hline \multicolumn{4}{|l|}{ Baseline seroprotection $^{c}$} \\
\hline $\mathrm{A} / \mathrm{H} 1 \mathrm{~N} 1$ & $32(63)$ & $58(57)$ & 0.49 \\
\hline $\mathrm{A} / \mathrm{H} 3 \mathrm{~N} 2$ & $24(47)$ & $70(69)$ & 0.01 \\
\hline B & $33(65)$ & $61(60)$ & 0.56 \\
\hline $\begin{array}{l}\text { Days between vaccination } \\
\text { and end-of-season visit }\end{array}$ & $\begin{array}{l}174.5 \\
(157-245)\end{array}$ & $\begin{array}{l}155 \\
(149-163.5)\end{array}$ & $<0.001$ \\
\hline
\end{tabular}

Values expressed as mean $\pm \mathrm{SD}$, number (\%), or median (25th-75th percentiles). Conversion factors for units: serum creatinine in $\mathrm{mg} / \mathrm{dl}$ to $\mathrm{mol} / \mathrm{l}, \times 88.4$.

${ }^{\text {a }}$ Race was self-reported.

b Previous influenza vaccination was self-reported.

${ }^{c}$ Baseline seroprotection defined as antibody titer $\geq 1: 32$ prior to vaccination.

er baseline geometric mean titer as well. Baseline seroprotection and geometric mean titers were similar in both groups for $\mathrm{A} / \mathrm{H} 1 \mathrm{~N} 1$ and $\mathrm{B}$.

Of the 153 participants, $122(79.7 \%)$ had a third visit with an end-of-season antibody titer obtained (fig. 1). Significantly fewer transplant recipients versus controls completed the third visit $(\mathrm{p}=0.004)$. The transplant group had significantly more time between their initial vaccination (visit 1) and end-of-season visit (visit 3). Otherwise those without a third visit did not differ from those with a third visit by age, sex, race, previous influenza vaccination history, or presence of baseline seroprotection to any of the vaccine types.

In the kidney transplant participants with a third visit, an equal number of recipients had received a living or deceased donor allograft (table 2). The median time since 
Table 2. Additional characteristics of the kidney transplant group with a third visit

\begin{tabular}{|c|c|}
\hline & Total $(\mathrm{n}=34)$ \\
\hline \multicolumn{2}{|l|}{ Type of transplant } \\
\hline Deceased donor & $17(50)$ \\
\hline Living & $17(50)$ \\
\hline Time since transplant, days & $240(70-657)$ \\
\hline \multicolumn{2}{|l|}{ Cause of kidney failure } \\
\hline Diabetes & $10(29.4)$ \\
\hline Polycystic kidney disease & $7(20.6)$ \\
\hline Glomerulonephritis & $6(17.6)$ \\
\hline Hypertension & $5(14.7)$ \\
\hline Obstruction & $3(8.8)$ \\
\hline Other/unknown & $3(8.8)$ \\
\hline First transplant & $29(85.3)$ \\
\hline Prior rejection episode & $4(11.8)$ \\
\hline \multicolumn{2}{|l|}{ Induction agent } \\
\hline Antithymocyte antiglobulin & $21(61.8)$ \\
\hline Basiliximab & $7(20.6)$ \\
\hline Alemtuzumab & $3(8.8)$ \\
\hline Other & $3(8.8)$ \\
\hline \multicolumn{2}{|l|}{ Immunosuppression regimen } \\
\hline Tacrolimus/MMF & $13(38.2)$ \\
\hline Tacrolimus/MMF/prednisone & $9(26.5)$ \\
\hline Tacrolimus/prednisone & $4(11.8)$ \\
\hline Tacrolimus/MPA & $4(11.8)$ \\
\hline Tacrolimus/MPA/prednisone & $3(8.8)$ \\
\hline Other & $1(2.9)$ \\
\hline Tacrolimus total daily dose, mg & $6(4-6.5)$ \\
\hline \multicolumn{2}{|l|}{ Tacrolimus dose-corrected trough level } \\
\hline$(\mathrm{ng} / \mathrm{ml}) / \mathrm{mg}$ & $1.3(1-1.7)$ \\
\hline $\mathrm{MMF} / \mathrm{MPA}$ use & $28(82.4)$ \\
\hline MMF total daily dose, $\mathrm{mg}$ & $2,000(1,000-2,000)$ \\
\hline MPA total daily dose, mg & $720(720-1,440)$ \\
\hline Prednisone use & $16(47.1)$ \\
\hline Antiviral prophylaxis, for CMV & $12(35.3)$ \\
\hline
\end{tabular}

Values expressed as median (25th-75th percentiles), or number (\%). MMF = Mycophenolate mofetil; MPA = mycophenolic acid; $\mathrm{CMV}=$ cytomegalovirus.

transplant was 240 days (IQR 70-657). The most common cause of end-stage renal disease was diabetes mellitus. Of the transplant recipients, $91 \%$ received induction therapy, with the majority receiving antithymocyte antiglobulin (61.8\%). Based on study design, all kidney transplant recipients were on a tacrolimus-based regimen with a median tacrolimus dose of $6 \mathrm{mg} /$ day (IQR 4-6.5) and median tacrolimus dose-corrected trough level of 1.3 (ng/ $\mathrm{ml}) / \mathrm{mg}$ (IQR 1-1.7). Almost half of the transplant group was on prednisone.

\section{Antibody Titers}

Geometric mean titers are shown in figure 2. The titers from post-vaccination to the end of season decreased significantly within each group for all three influenza types using the Wilcoxon signed rank test $(\mathrm{p}<0.001$ for all three types for both groups). Using linear regression, differences between antibody titers between the two groups at the end of season were assessed. Adjustment was made for titer at 1 month, age, sex, race, and baseline serum creatinine. The end-of-season vaccination titer was not significantly different between the control and transplant groups for all three types. We next used a linear mixedeffects model to assess the titer change over all study time between the two groups. The fixed effects included age, sex, race, baseline creatinine, observation time, group, and observation time by group interaction. Using this model the titer changes over time were statistically significant between the groups for all three influenza types.

\section{Primary Outcome}

The proportion of participants who maintained a protective antibody response throughout the study period for each influenza antigen type is shown in table 3 . The starting cohort number is different for each type as it represents those who developed seroprotection at 1 month post-vaccination for that particular type. For influenza types $\mathrm{A} / \mathrm{H} 1 \mathrm{~N} 1$ and $\mathrm{B}$, the proportion of participants in the transplant and control groups who maintained a protective antibody response was not different between the groups. For A/H3N2, a significantly lower proportion of the transplant group remained seroprotected with a titer $\geq 32$ at the end of season compared with healthy controls, 66.7 versus $90.4 \%$, respectively. The transplant group had 0.21 decreased odds of maintaining seroprotection $(95 \%$ confidence interval $0.07-0.64, \mathrm{p}=0.006$ ) compared with healthy controls.

Given that the transplant group had a significantly lower baseline geometric mean titer than the healthy control group for $\mathrm{A} / \mathrm{H} 3 \mathrm{~N} 2$ and a difference was seen in maintenance of seroprotection, analyses were performed using multivariate logistical regression that adjusted for titer at 1 month as well as a propensity score for age, sex, race, and baseline serum creatinine. Once adjusted, the difference for $\mathrm{A} / \mathrm{H} 3 \mathrm{~N} 2$ at the end of season was no longer significant.

No adverse events were reported by any of the study participants, including no rejection episodes or graft loss in the transplant group. Two control participants and no transplant participants reported influenza-like illness without hospitalization over the study period. 
Fig. 2. Serologic response to the 20062007 inactivated influenza vaccine expressed as geometric mean titers for the 123 participants. For control group: A/ H1N1 pre 35.8 , post 113.7 , end 60.1 ; A/ $\mathrm{H} 3 \mathrm{~N} 2$ pre 41 , post 210.9 , end 78.1 ; B pre 41.5, post 150.4 , end 69.7. For transplant group: A/H1N1 pre 39.2, post 68.1, end 44; A/H3N2 pre 22, post 49.2 , end 26.8 ; B pre 39.2 , post 87.5 , end 45.7 .

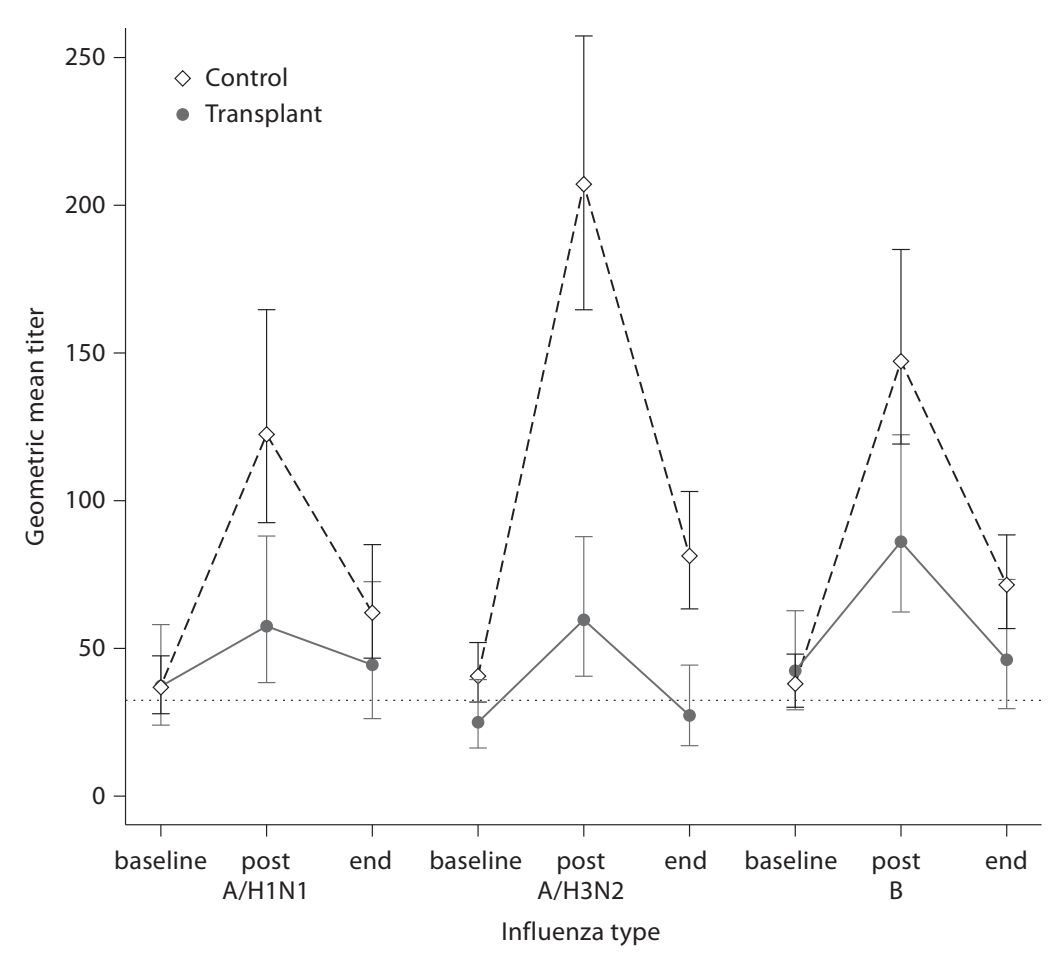

Table 3. Proportion of vaccinated participants who maintained protective antibody response throughout the 2006-2007 influenza season by each antigen subtype

\begin{tabular}{|c|c|c|c|c|c|c|c|c|}
\hline Seroprotection & $\begin{array}{l}\text { Transplant } \\
\text { recipients }\end{array}$ & Controls & $\begin{array}{l}\text { Unadjusted } \\
\text { odds ratio }\end{array}$ & $95 \% \mathrm{CI}$ & $\mathrm{p}$ & $\begin{array}{l}\text { Adjusted } \\
\text { odds ratio }\end{array}$ & $95 \% \mathrm{CI}$ & $\mathrm{p}$ \\
\hline $\mathrm{A} / \mathrm{H} 1 \mathrm{~N} 1(\mathrm{n}=102)$ & $\begin{array}{l}\mathrm{n}=26 \\
23(88.5 \%)\end{array}$ & $\begin{array}{l}\mathrm{n}=76 \\
62(81.6 \%)\end{array}$ & 1.73 & $0.46-6.58$ & 0.42 & 3.19 & $0.39-25.9$ & 0.28 \\
\hline $\mathrm{A} / \mathrm{H} 3 \mathrm{~N} 2(\mathrm{n}=108)$ & $\begin{array}{l}\mathrm{n}=24 \\
16(66.7 \%)\end{array}$ & $\begin{array}{l}\mathrm{n}=84 \\
76(90 \%)\end{array}$ & 0.21 & $0.07-0.64$ & 0.006 & 0.52 & $0.08-3.29$ & 0.49 \\
\hline $\mathrm{B}(\mathrm{n}=117)$ & $\begin{array}{l}\mathrm{n}=31 \\
23(74.2 \%)\end{array}$ & $\begin{array}{l}\mathrm{n}=86 \\
72(83.7 \%)\end{array}$ & 0.56 & $0.21-1.5$ & 0.25 & 1.28 & $0.24-6.88$ & 0.78 \\
\hline
\end{tabular}

Model adjusted for titer at 1 month and propensity score for age, sex, race, and baseline creatinine.

\section{Discussion}

In this prospective cohort study, we showed that once a protective antibody response is successfully developed, kidney transplant recipients are able to maintain the response as effectively for $\mathrm{A} / \mathrm{H} 1 \mathrm{~N} 1, \mathrm{~A} / \mathrm{H} 3 \mathrm{~N} 2$, and $\mathrm{B}$ types throughout the influenza season once adjusted for other covariates. Several studies have reported the initial antibody response to influenza vaccine in kidney transplant recipients, some showing a comparable and others showing a diminished response compared with healthy controls [7-9]. In a previous study, we showed that the proportion of kidney transplant recipients who developed seroconversion or seroprotection to the 2006-2007 seasonal 
inactivated influenza vaccine at 1 month post-vaccination was lower for some types, especially for patients within 6 months of transplantation. However, little information exists about what happens to this response over the duration of the influenza season as patients continue to be immunosuppressed by their transplant medications.

When considering all three types, the proportion of the transplant group remaining adequately protected ranged from 66.7 to $88.5 \%$, showing that the great majority of kidney transplant recipients are able to maintain a protective response to influenza vaccination throughout the influenza season once they develop an initial protective response. Even though the seroprotective response to A/H3N2 was statistically significantly less in kidney transplant recipients in unadjusted analyses, in reality about two thirds (66.7\%) maintained a seroprotective response showing the majority of patients will maintain a protective titer. This supports seasonal influenza vaccination in kidney transplant recipients, concurring with the official recommendations by the American Society for Transplantation and Centers for Disease Control and Prevention [2, 3].

For healthy control participants, previous studies have shown that after the initial antibody response occurs within the first month post-vaccination, antibody titers and responses persist for several months until the next influenza season. For example, Künzel et al. [22] showed that geometric mean titers and protective antibody responses at 280 days were consistent with those seen at 7 days. In addition, $71-100 \%$ of vaccinees continued to have protective antibody responses at 280 days. The median follow-up time for our cohort was 174.5 and 155 days for the transplant and healthy control groups respectively, falling within the above time frame. Our results in kidney transplant recipients are consistent with those of healthy controls, showing that though immunosuppressed, the transplant recipients are able to maintain an adequate protective antibody response throughout the influenza season. However, titers in both groups did wane, reinforcing the importance of annual vaccination.

A limitation of this study is the use of a surrogate endpoint, antibody titer, for actual clinical outcomes, like documented influenza illness or hospitalization/death related to influenza-like illness. Participants were asked about subjective influenza-like illness at each visit, but they were not actively tested for infection, limiting detection of actual influenza infection. A recent large retrospective study of over 51,000 Medicare patients with kidney transplants did show that influenza vaccination was associated with a lower risk of graft loss and death [23]. Another limitation is the small cohort sample size, increasing the possibility that we may not be able to detect a difference between the transplant and control groups even if one really exists.

In summary, we show that kidney transplant patients are able to maintain season long immunoprotection against different types of influenza. While a future prospective study with a larger sample size and matched controls with relevant clinical outcomes could be helpful in further understanding influenza vaccine response, current recommendations should include continued annual vaccination in kidney transplant recipients.

\section{Acknowledgements}

Supported in part by Vanderbilt CTSA grant 1 UL1 RR024975 from the National Center for Research Resources, National Institutes of Health; NIH/NRSA Training Grant 5 T32 DK007569-17; K24 DK62849 from the National Institute of Diabetes, Digestive and Kidney Diseases, and 1 K23 GM100183-01 from the National Institute of General Medical Sciences.

\section{Disclosure Statement}

The authors have no conflicts of interest to disclose.

\section{References}

1 Kotton CN, Fishman JA: Viral infection in the renal transplant recipient. J Am Soc Nephrol 2005;16:1758-1774.

-2 Danzinger-Isakov L, Kumar D: Guidelines for vaccination of solid organ transplant candidates and recipients. Am J Transplant 2009;9(suppl 4):S258-S262.

3 Fiore AE, Uyeki TM, Broder K, Finelli L, Euler GL, Singleton JA, Iskander JK, Wortley PM, Shay DK, Bresee JS, Cox NJ: Prevention and control of influenza with vaccines: recommendations of the Advisory Committee on Immunization Practices (ACIP), 2010. MMWR Recomm Rep 2010;59:1-62.

4 Vilchez RA, Fung J, Kusne S: The pathogenesis and management of influenza virus infection in organ transplant recipients. Transpl Infect Dis 2002;4:177-182.

5 Edwards KM, Dupont WD, Westrich MK, Plummer WD Jr, Palmer PS, Wright PF: A randomized controlled trial of cold-adapted and inactivated vaccines for the prevention of influenza A disease. J Infect Dis 1994;169: 68-76.

6 Birdwell KA, Ikizler MR, Sannella EC, Wang L, Byrne DW, Ikizler TA, Wright PF: Decreased antibody response to influenza vaccination in kidney transplant recipients: a prospective cohort study. Am J Kidney Dis 2009;54:112-121. 
7 Scharpe J, Evenepoel P, Maes B, Bammens B, Claes K, Osterhaus AD, Vanrenterghem Y, Peetermans WE: Influenza vaccination is efficacious and safe in renal transplant recipients. Am J Transplant 2008;8:332-337.

8 Keshtkar-Jahromi M, Argani H, Rahnavardi M, Mirchi E, Atabak S, Tara SA, Gachkar L, Noori-Froothghe A, Mokhtari-Azad T: Antibody response to influenza immunization in kidney transplant recipients receiving either azathioprine or mycophenolate: a controlled trial. Am J Nephrol 2008;28:654-660.

-9 Cavdar C, Sayan M, Sifil A, Artuk C, Yilmaz N, Bahar H, Camsari T: The comparison of antibody response to influenza vaccination in continuous ambulatory peritoneal dialysis, hemodialysis and renal transplantation patients. Scand J Urol Nephrol 2003;37:7176.

-10 Sanchez-Fructuoso AI, Prats D, Naranjo P, Fernandez-Perez C, Gonzalez MJ, Mariano A, Gonzalez J, Figueredo MA, Martin JM, Paniagua V, Fereres J, Gomez de la Concha $\mathrm{E}$, Barrientos A: Influenza virus immunization effectivity in kidney transplant patients subjected to two different triple-drug therapy immunosuppression protocols: mycophenolate versus azathioprine. Transplantation 2000;69:436-439.

- 11 Kumar SS, Ventura AK, VanderWerf B: In fluenza vaccination in renal transplant recipients. JAMA 1978;239:840-842.
12 Huang KL, Armstrong JA, Ho M: Antibody response after influenza immunization in renal transplant patients receiving cyclosporin A or azathioprine. Infect Immun 1983; 40:421-424.

13 Briggs WA, Rozek RJ, Migdal SD, Shillis JL, Brackett RG, Brandon FB, Mahajan SK, McDonald FD: Influenza vaccination in kidney transplant recipients: cellular and humoral immune responses. Ann Intern Med 1980 92:471-477.

14 Versluis DJ, Beyer WE, Masurel N, Wenting GJ, Weimar W: Impairment of the immune response to influenza vaccination in renal transplant recipients by cyclosporine, but not azathioprine. Transplantation 1986;42: 376-379.

15 Schwartz B, Martin SW: Principles of epidemiology and public health; in Long SS (ed): Principles and Practice of Pediatric Infectious Diseases, ed 3. Philadelphia, Elsevier, 2008.

16 CPMP: Note for guidance on harmonisation of requirements for influenza vaccines 1997

17 Fox JP, Hall CE, Cooney MK, Foy HM: Influenza virus infections in Seattle families, 1975-1979. I. Study design, methods and the occurrence of infections by time and age. Am J Epidemiol 1982;116:212-227.

18 Warburton MF: Immunization against influenza. Med J Aust 1972;1:546-547.
19 Rudenko LG, Slepushkin AN, Monto AS, Kendal AP, Grigorieva EP, Burtseva EP, Rekstin AR, Beljaev AL, Bragina VE, Cox N, et al: Efficacy of live attenuated and inactivated influenza vaccines in schoolchildren and their unvaccinated contacts in Novgorod, Russia. J Infect Dis 1993;168:881-887.

20 Levey AS, Coresh J, Greene T, Stevens LA, Zhang YL, Hendriksen S, Kusek JW, Van Lente F: Using standardized serum creatinine values in the modification of diet in renal disease study equation for estimating glomerular filtration rate. Ann Intern Med 2006;145:247-254.

21 Kendal AP, Skehel JJ, Pereira MS: Concepts and Procedures for Laboratory-Based Influenza Surveillance. Atlanta, US Department of Health and Human Services, Public Health Service, Centers for Disease Control, 1982.

22 Künzel W, Glathe H, Engelmann H, Van Hoecke C: Kinetics of humoral antibody response to trivalent inactivated split influen$z a$ vaccine in subjects previously vaccinated or vaccinated for the first time. Vaccine 1996; 14:1108-1110.

23 Hurst FP, Lee JJ, Jindal RM, Agodoa LY, Abbott KC: Outcomes associated with influen$\mathrm{za}$ vaccination in the first year after kidney transplantation. Clin J Am Soc Nephrol 2011;6:1192-1197. 